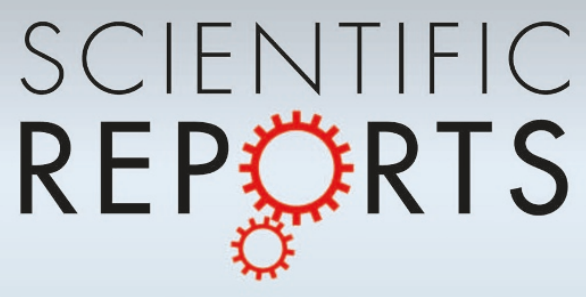

OPEN

SUBJECT AREAS:

BEHAVIOURAL ECOLOGY

EVOLUTIONARY ECOLOGY

COEVOLUTION

ENTOMOLOGY

Received

10 January 2013

Accepted

29 May 2013

Published

20 June 2013

Correspondence and requests for materials should be addressed to R.N. (rnakano@affrc. go.jp)

\section{Evolution of deceptive and true courtship songs in moths}

\author{
Ryo Nakano ${ }^{1,2}$, Takuma Takanashi ${ }^{3}$, Annemarie Surlykke ${ }^{4}$, Niels Skals ${ }^{4} \&$ Yukio Ishikawa
}

\begin{abstract}
'Graduate School of Agricultural and Life Sciences, The University of Tokyo, Bunkyo-ku, Tokyo 1 13-8657, Japan, ${ }^{2}$ Breeding and Pest Management Division, NARO Institute of Fruit Tree Science, Tsukuba, lbaraki 305-8605, Japan, ${ }^{3}$ Department of Forest Entomology, Forestry and Forest Products Research Institute, Tsukuba, Ibaraki 305-8687, Japan, ${ }^{4}$ Sound and Behavior Group, Institute of Biology, University of Southern Denmark, DK-5230, Odense M, Denmark.
\end{abstract}

Ultrasonic mating signals in moths are argued to have evolved via exploitation of the receivers' sensory bias towards bat echolocation calls. We have demonstrated that female moths of the Asian corn borer are unable to distinguish between the male courtship song and bat calls. Females react to both the male song and bat calls by "freezing", which males take advantage of in mating (deceptive courtship song). In contrast, females of the Japanese lichen moth are able to distinguish between the male song and bat calls by the structure of the sounds; females emit warning clicks against bats, but accept males (true courtship song). Here, we propose a hypothesis that deceptive and true signals evolved independently from slightly different precursory sounds; deceptive/true courtship songs in moths evolved from the sounds males incidentally emitted in a sexual context, which females could not/could distinguish, respectively, from bat calls.

$\mathrm{t}$ is argued that sexual communication in some systems has evolved via the exploitation of mating partners' sensory bias towards prey or predator cues ${ }^{1-5}$. The exploitation of prey-related cues to seduce a mate (sensory trap) has been evidenced in several animals, including goodeinae fish, swordtail characins, and a water mite ${ }^{5-7}$. In contrast, it has been difficult to find evidence for the exploitation of receiver's sensory bias towards predator cues because the signal receivers examined had already evolved the ability to distinguish between predator cues and mate's signals: receivers evade predator cues, but prefer mate's signals ${ }^{8,9}$.

In acoustic signaling moths, the evolution of ultrasound detection is believed to have preceded the development of intraspecific ultrasonic communication ${ }^{3,9,10}$. Moths first evolved ears that detect the ultrasonic echolocation calls of insectivorous bats to avoid predation ${ }^{9,11-13}$. Subsequently, some moths evolved sound-producing organs and, thereafter, acoustic sexual communication ${ }^{9-11}$. The sensory bias that had developed for detecting bat calls should have constrained the basic design of ultrasonic signals in moths ${ }^{1,3,4,8,11}$. The classic sensory bias model of signal evolution assumes that tuning of the signal design to the receiver's preference subsequently evolved through coevolutionary sexual selection ${ }^{1-7}$. The lesser wax moth Achroia grisella (Pyraloidea, Pyralidae), in which the characteristics of ultrasonic advertisement signals emitted by males matches the female receivers' preference, is often given as a possible example of the sensory bias model ${ }^{3,48,14}$. However, there is actually no proof for the assumption that female receivers were initially unable to discriminate between bat calls and males' precursory advertisement sounds.

In our previous studies ${ }^{15-17}$, we found that male moths of the Asian corn borer Ostrinia furnacalis (Pyraloidea, Crambidae) produce an ultrasonic courtship song of extremely low-intensity after landing close to a female showing calling behavior (protruding her abdominal tip to release sex pheromones). This song has been shown to significantly increase the mating success of the male; behavioral experiments using pairs with deafened females or muted males suggested that the ultrasonic songs of the male render the females motionless (freezing), which increases the success rate of a single copulation attempt by the male. To explain the effect of courtship songs in $O$. furnacalis, we proposed a 'predator recognition' hypothesis, which assumes that females of $O$. furnacalis are not able to distinguish between male courtship songs and bat calls ${ }^{16,17}$. However, this hypothesis has yet to be tested.

The finding of an ultrasonic courtship song of extremely low-intensity in a moth prompted us to survey similar courtship songs in other moth species ${ }^{18}$. In this survey, we found that males of the Japanese lichen moth, Eilema japonica japonica (Noctuoidea, Arctiidae), also produce ultrasonic courtship songs of low intensity in the proximity of the female ${ }^{18}$. Five arctiid species (tiger moths) have already been demonstrated to use ultrasonic clicks as mating signals ${ }^{10,19,20}$. Here, it should be noted that both sexes of many arctiid moths emit defensive ultrasonic clicks that function as warning or jamming signals against attacking bats ${ }^{10,12,21-23}$. Eilema japonica was not an exception; we found that both sexes of this species also emit defensive ultrasonic clicks against bat calls. 

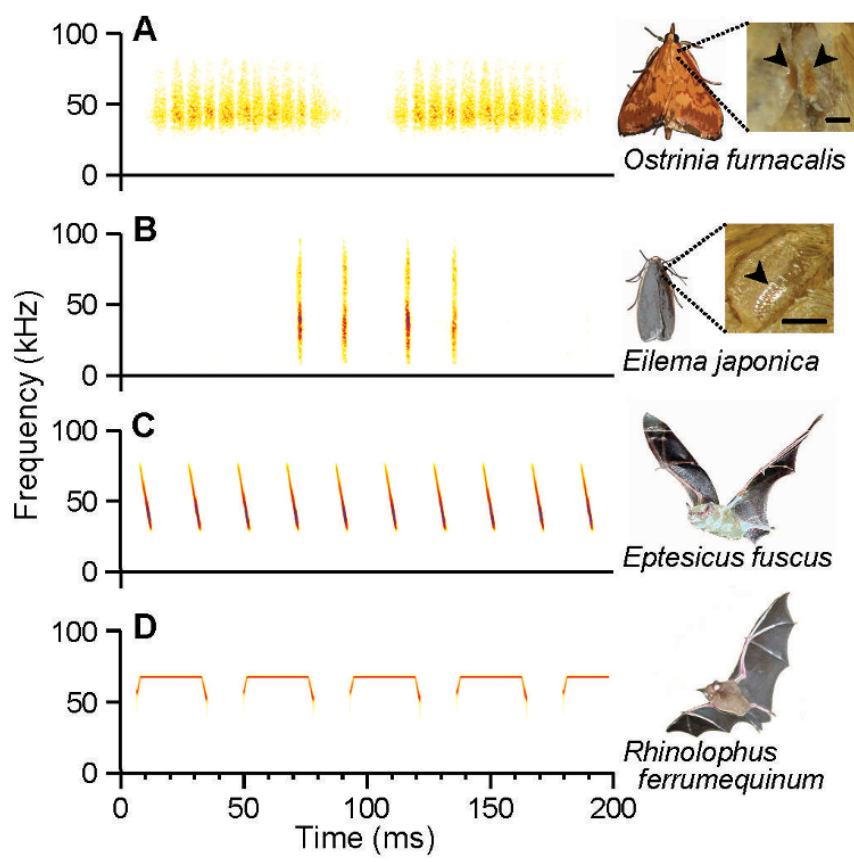

Figure 1 Examples of sound stimuli. Male songs of (A) the Asian corn borer Ostrinia furnacalis and (B) the Japanese lichen moth Eilema japonica japonica. Simulations of terminal phase calls of (C) the big brown bat Eptesicus fuscus (FM bat) and (D) the Japanese greater horseshoe bat Rhinolophus ferrumequinum nippon (CF bat). Magnified images of soundproducing organs, forewing and thoracic scales of the Asian corn borer and a thoracic tymbal of the Japanese lichen moth, are also shown. Scale bar, $500 \mu \mathrm{m}$. Images of bats are courtesy of J. A. Simmons and S. Hiryu (E. fuscus), and Y. Sato (R. f. nippon).

Given that arctiid female moths respond to mating clicks and bat calls differently, they are likely to distinguish between the two sounds.

In the present study, we tested whether female receivers distinguish between conspecific male courtship songs and bat echolocation calls in sexual as well as non-sexual contexts using two unrelated species of moths, O. furnacalis and E. japonica. Based on the findings, we proposed a working hypothesis on the evolution of deceptive and true sexual communication in moths.

\section{Results}

Sound discrimination in the Asian corn borer. We first tested the ability of the female moths of the Asian corn borer to discriminate between the male courtship song (Figure 1A) and bat calls (Figure 1C, 1D) in the context of mate acceptance. The mating success of sham-operated males, which emit the courtship song apparently normally, was high ( $>80 \%$; Figure $2 \mathrm{~A})$. In experiments using muted males, smaller proportions of females accepted males when no sound or background noise was broadcast [Likelihood ratio test (LRT) in generalized linear model (GLM), $\mathrm{p}=0.0018$ and $\mathrm{p}=$ 0.057 , respectively] (Figure 2A). In contrast, the mating success of muted males was not significantly different from that of the shamoperated males when either a male song, frequency-modulation (FM) bat call, constant-frequency (CF) bat call, or $40 \mathrm{kHz}$ sinewave tone was broadcast $(\mathrm{p}=0.24, \mathrm{p}=0.65, \mathrm{p}=1.00$, and $\mathrm{p}=$ 0.24 , respectively) (Figure $2 \mathrm{~A}$ ).

The escape behavior of the female, which results in mate rejection, has been shown to be suppressed by the male song ${ }^{16,17}$. We evaluated the suppressive effect of different sound stimuli on female escape behavior by using muted-and-deafened males with artificially damaged genital claspers. These males were unable to copulate and, thus, persistently repeated copulation attempts. The effect of playbacks was evaluated by the number of copulation attempts the male could repeat before the female escaped ${ }^{16}$. The males were deafened in order to exclude the possibility of an unintended influence of the playbacks on them. The broadcasted male song, FM bat call, CF bat call, or $40 \mathrm{kHz}$ sine wave was as effective as the natural male song (LRT in GLM, $\mathrm{p}=0.21, \mathrm{p}=0.78, \mathrm{p}=0.91$, and $\mathrm{p}=0.19$ ), while no sound or noise was not $(\mathrm{p}=0.00027$ and $\mathrm{p}=0.00079)$ (Figure $2 \mathrm{~B})$.

Females showing calling behavior ceased this behavior in response to bat echolocation calls, a startle response exhibited by the females ${ }^{24}$. We examined whether conspecific male songs also interrupted the females' calling behavior. The majority of females $(>73 \%)$ stopped exposing the pheromone gland in response to all sound stimuli broadcast at high sound pressure levels $(>74 \mathrm{~dB})$ (Figure 2C-F). FM and CF bat calls had the same level of effect as the male song (LRT in GLM, p = 1.00 and $\mathrm{p}=0.34$ ), while a 40$\mathrm{kHz}$ sine-wave tone was significantly less effective $(\mathrm{p}=0.023)$ (Figure 2G).

The majority ( $>78 \%$ ) of tethered flying corn borer moths showed evasive behavior (diving, looping flight, or steep turns) in response to loud sound stimuli $(98 \mathrm{~dB})$ with no difference in responsiveness between sexes [LRT in generalized linear mixed model (GLMM), p $=0.17$ ] (Figure $2 \mathrm{H}-\mathrm{K}$ ). These experiments demonstrated that flying moths were unable to distinguish between conspecific songs and bat (FM or CF) calls (LRT in GLM, $\mathrm{p}=0.36$ and $\mathrm{p}=0.84$ ). The sine wave was significantly less effective in eliciting the evasive response $(\mathrm{p}<0.0001)$ (Figure 2L).

Examinations of the effect of sound broadcast on mating success, suppression of the female's escape behavior, disruption of pheromone release, and evasive flight, all showed that females (and males) of the Asian corn borer were unable to distinguish between ultrasounds emitted by conspecific males and bat calls. It is now clear that, to increase mating success, males of this species suppress the female's escape behavior by exploiting her freezing response to bats (Deceptive courtship song; Figure 2B). Females accepted muted males even when a sine wave tone was broadcast (Figure 2A), which suggests that a specific temporal structure is not required for sound recognition by females. However, since a continuous sine wave was less effective in eliciting evasive responses (Figure 2L), a pulsed structure (Figure 1A, 1C, 1D) seems to be a key feature for the recognition of bat-like sounds.

Sound discrimination in the Japanese lichen moth. We then examined sound discrimination between male ultrasonic clicks (Figure 1B) and bat calls (Figure 1C, 1D) in the Japanese lichen moth Eilema japonica. When females were deafened or males were muted, female lichen moths rejected males in the course of courtship (LRT in GLM, $\mathrm{p}=0.0010$ and $\mathrm{p}=0.00094$ ) (Figure 3A). In contrast, the ablation of female tymbals (muting) had no effect on mating success $(p=0.97)$. Thus, acoustic sexual communication with male ultrasonic clicks was verified in this species. Females accepted muted males when a synthetic male song was broadcast (LRT in GLM, $\mathrm{p}=0.26$ ), but not when background noise or a simulated FM or CF bat call was broadcast $(\mathrm{p}=0.0028, \mathrm{p}<0.0001$ and $\mathrm{p}<$ 0.0001 ) (Figure $3 \mathrm{~B}$ ). These results demonstrate that female lichen moths recognize male ultrasonic clicks as a mating signal (True courtship song).

Stationary lichen moths of both sexes reacted to CF bat calls by emitting consecutive ultrasonic clicks (phonoresponse) (Figure 3C), which differed from the courtship song in the frequency of clicks [male courtship song: $5.36 \pm 1.39$ clicks/100 ms (mean \pm SD), phonoresponse: $32.56 \pm 18.11$, LRT in GLMM, p $<0.0001]$. We observed a weaker, but significant phonoresponse to FM bat calls (LRT in GLMM, p = 0.0077), but no response to the male song (Figure 3C). Flying tethered lichen moths showed a phonoresponse (Figure 3D) and/or evasive behavior (Figure 3E) in response to the 

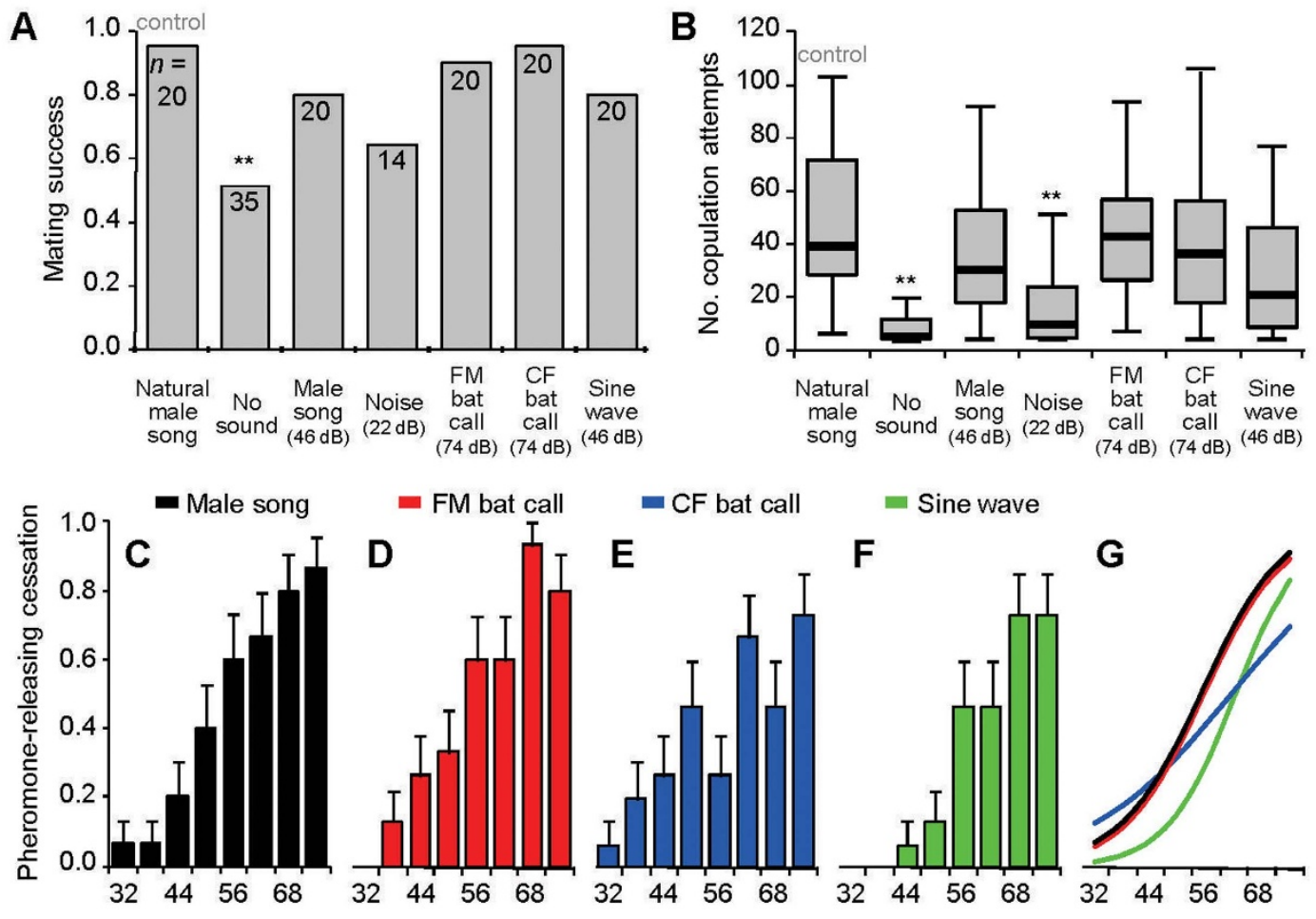

$$
\text { Sine wave }
$$

$\mathbf{F}$
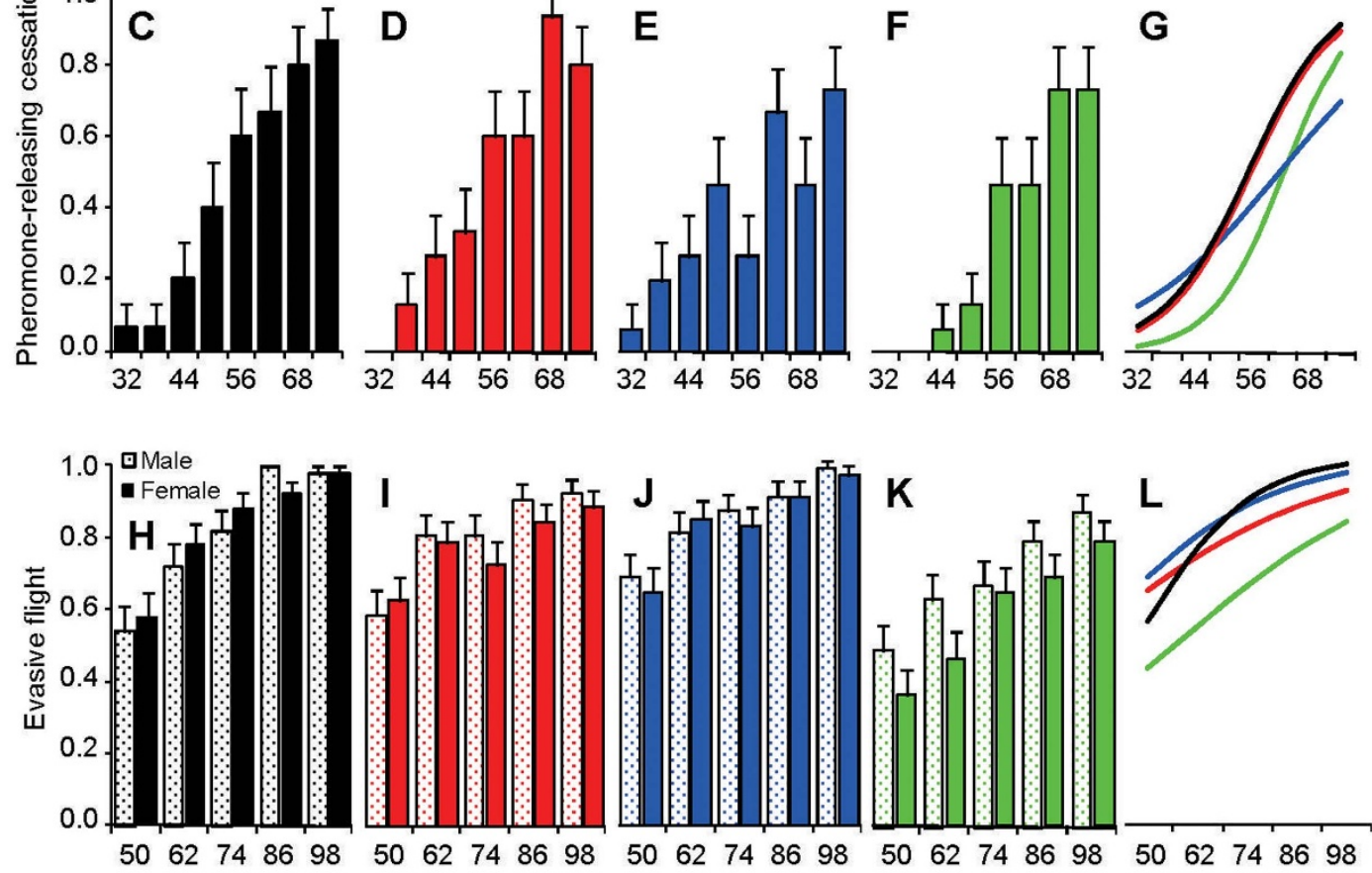

Amplitude of sound stimulus (dB SPL)

Figure $2 \mid$ Effects of sound stimuli on the mating success and bat-avoidance responses in the Asian corn borer. (A) Mating success of intact females with muted males under the influence of different sound stimuli. Sample sizes are denoted on each column. (B) The number of copulation attempts that a courting male, which could not achieve copulation by artificially damaged genital claspers, could repeat while the female remained stationary by different sound stimuli. A large number means that the females' escape behavior was suppressed in the course of courtship. Box-and-whisker plots show the median, first/third quartile, and range within 1.5 times the difference between each quartile and median. $\mathrm{n}=20$ pairs in each stimulus. The natural male song indicates the sound produced by sham-operated male, which served as a positive control (A, B). **p $<0.01$. (C-G) Proportion of females that ceased releasing sex pheromone in response to sound stimuli. $\mathrm{n}=15$ females in each combination of sound stimuli and sound levels ( $\mathrm{n}=120$ in each sound stimulus; $\mathrm{n}=480$ in total). ( $\mathrm{H}-\mathrm{L}$ ) Proportion of tethered moths that showed evasive flight. $\mathrm{n}=5-6$ males and 5-6 females with 5-15 replicates in each combination of sound stimuli and sound levels. Effects of $(\mathrm{C}, \mathrm{H})$ male song playback, (D, I) simulated FM bat calls, (E, J) simulated CF bat calls, and (F, K) a continuous sine wave. Error bars represent the standard error of the mean. $(\mathrm{G}, \mathrm{L})$ Logistic regression curves for each stimulus. Some data were obtained from our previous studies ${ }^{16}$.

sounds tested. With respect to the phonoresponse, a significantly smaller proportion of moths responded to the playback of male songs than to FM bat calls (LRT in GLMM, $\mathrm{p}=0.0065$ ) and CF bat calls ( $\mathrm{p}$ $<0.0001$ ) (Figure 3D). Regarding evasive behavior during flying, a significantly smaller proportion of moths reacted to the male song than to bat calls (LRT in GLMM, p $<0.0001$ for both FM and CF bat calls) (Figure $3 \mathrm{E}$ ). The same was true when the phonoresponse and evasive response were combined for analysis (LRT in GLMM, p = 0.0044 for FM bat call and $\mathrm{p}<0.0001$ for CF bat call) (Figure 3F). Hence, the male song was most likely not perceived as an immediate predatory threat. These results clearly demonstrate that lichen moths are able to distinguish between the male song and bat calls.

\section{Discussion}

We have demonstrated that female moths of the Asian corn borer do not distinguish between conspecific male courtship songs and bat echolocation calls in sexual as well as non-sexual contexts (Figure 4A), whereas female moths of the Japanese lichen moth do (Figure 4B). Male courtship ultrasounds in the former species work as deceptive signals, whereas as true signals in the latter (Figure 4C).

The structure/location of sound-producing organs and type of acoustic communication in acoustic signaling moths may differ within members of the same family, which share the same hearing organ in terms of structure/location (Figure 5). These findings indicate that sound-producing organs as well as acoustic communication 

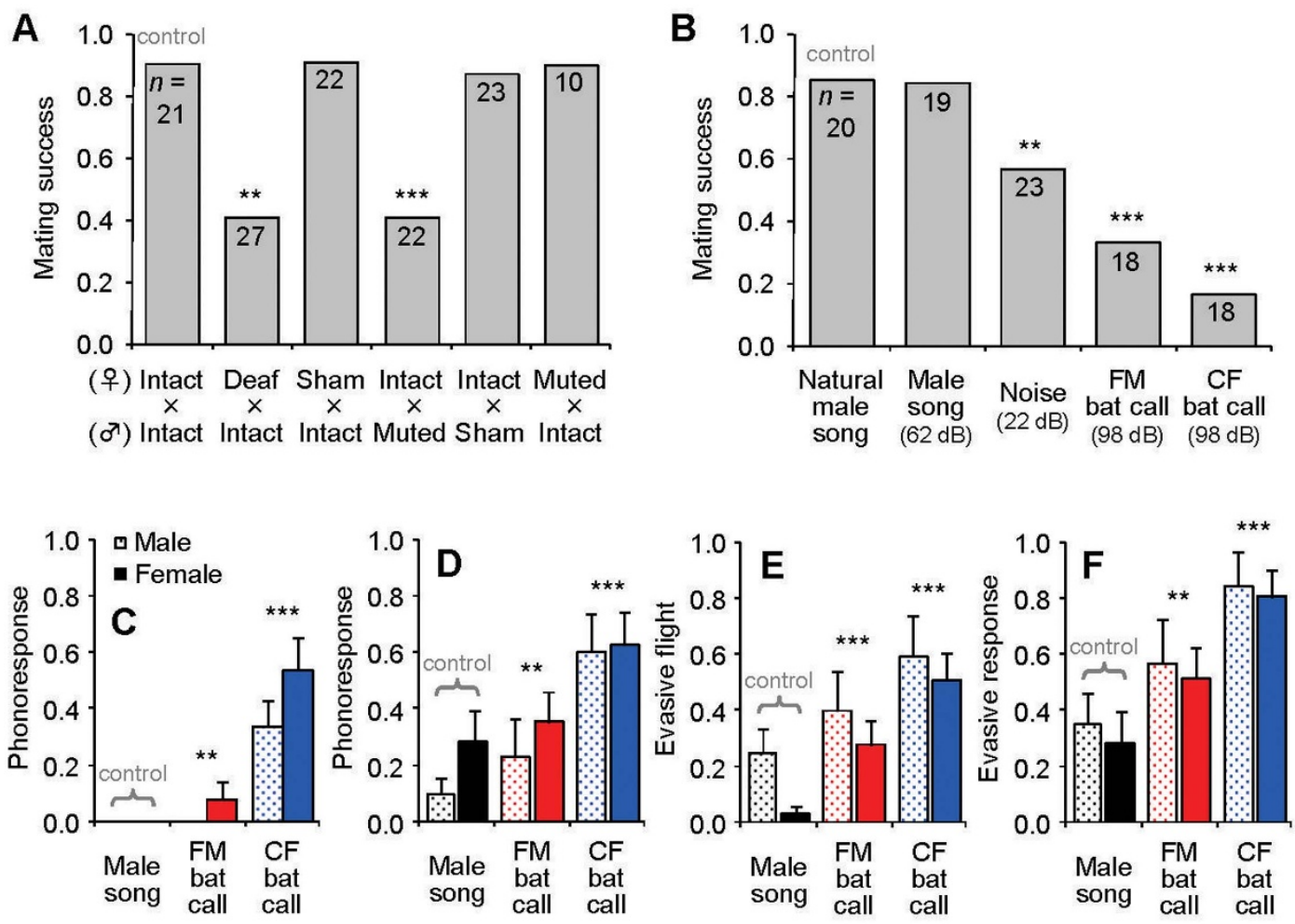

Figure 3 Effects of sound stimuli on the mating success and bat-avoidance responses in the Japanese lichen moth. (A) Mating success between females (O) and males $\left(\mathrm{O}^{*}\right)$, which underwent different surgical operations. Intact pairs served as a positive control. Sample sizes are denoted on each column. (B) Mating success of intact females with muted males under the influence of different sound stimuli. The natural male song indicates the sound produced by sham-operated male, which served as a positive control. Sample sizes are denoted on each column. (C) Phonoresponse (click production) of stationary moths to different sound stimuli. $\mathrm{n}=10$ males and 10-13 females with 5 replicates in each sound stimulus. (D) Phonoresponse, (E) evasive flight response, and (F) the sum of the phonoresponses and evasive flight responses of tethered flying moths to sound stimuli. Note that some moths showed both responses to a single stimulus. $\mathrm{n}=6-8$ males and 9-10 females with 3-10 replicates in each sound stimulus. Stimuli were all presented at $98 \mathrm{~dB}$ at the position of the moth. The male song served as a positive control in C-F. Error bars represent the standard error of the mean. ${ }^{* *} \mathrm{p}<0.01$ and $* * * \mathrm{p}<0.0001$.

evolved independently in different groups after the evolution of ultrasound-sensitive ears in the common ancestor. Moths cannot discriminate sound tones because the few auditory sensory cells in their ears have similar optimum frequencies and auditory tuning curves, and also attach to the same point on the tympanic membrane $^{11,25,26}$. Hence, pulse duration, interval, and intensity are the only information available for moths to distinguish between the auditory signals from conspecific mates and those from bats ${ }^{14,27-29}$. In the lesser wax moth, the short pulse length $(100 \mu \mathrm{s})$ and high pulse rate $(>60$ pulses/s) of male advertisement calls are essential for female attraction: females do not orient toward bat echolocation calls, which exhibit longer pulse lengths and lower pulse rates ${ }^{3,8,14}$. Our findings suggest that the lichen moth also distinguishes the male song from bat calls by a lower frequency of clicks (groups of 2-8 clicks lasting 50-85 ms are produced with 500-700 ms silent intervals $)^{18}$ (Figure 1B-D).

The Asian corn borer, in contrast, is not able to distinguish between the male song and bat calls. Therefore, female corn borer moths react to the song of a nearby male as they do to bat echolocation calls emitted from afar; females stop moving as if to avoid being detected by a bat. This freeze response is advantageous to males in repeating copulation attempts ${ }^{16,17}$ [see also reference ${ }^{30}$ for the common cutworm Spodoptera litura (Noctuoidea, Noctuidae)]. Under these conditions, no strong selective force that drives females to distinguish the male song from bat calls acts on females; thus, the male song would be maintained as a deceptive signal (Figure 4C).

Our findings of two different types of responses (freezing and mate recognition) to male ultrasounds in two species of moths have led us to the following working hypotheses on the evolution of acoustic communication in moths (Figure 4C). i) Ultrasound hearing in moths originally evolved as a countermeasure to the ultrasonic echolocation calls of bats. ii) Some species incidentally emitted faint ultrasounds, hearable to the receiver, probably in association with mating behaviors such as wing-fluttering for the delivery of the male sex pheromone toward females?. iii) When the sound males emitted was indistinguishable from bat calls, it developed into a deceptive courtship song. iv) In contrast, when the sound was different enough from bat calls to be distinguishable by the female receiver, it developed into a true courtship song through coevolutionary sexual selection processes ${ }^{1-4,8-10}$. In brief, we conceive that mating signals in acoustic moths have functionally diverged subject to the degree of similarity between bat calls and the sounds males incidentally emitted probably in association with mating behaviors.

\section{Methods}

Sound discrimination tests were conducted in the context of mate acceptance (successful copulation) and pheromone-release behavior in the female corn borer moth, and mate acceptance in the female lichen moth. To demonstrate sound discrimination in a context unrelated to mating, evasive responses of tethered flying moths were investigated using both sexes of the two species. In the Japanese lichen moth, the phonoresponse to sound stimuli was also examined using stationary and flying moths.

Statistical analyses were performed using software R ver. 2.14.0. Generalized linear mixed models (GLMM) and generalized linear models (GLM) were used for the analysis of data from experiments with and without the repeated use of the same individuals, respectively. In these models, we applied a binomial error distribution with a logit link function for analyzing mating and bat-avoidance responses in both the Asian corn borer and Japanese lichen moths, and a negative binomial error 
A

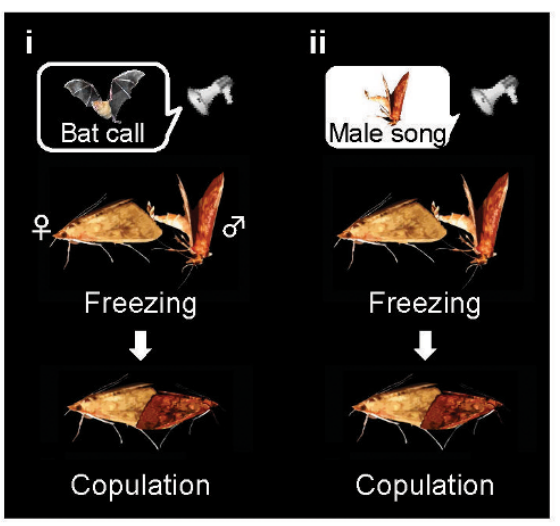

B

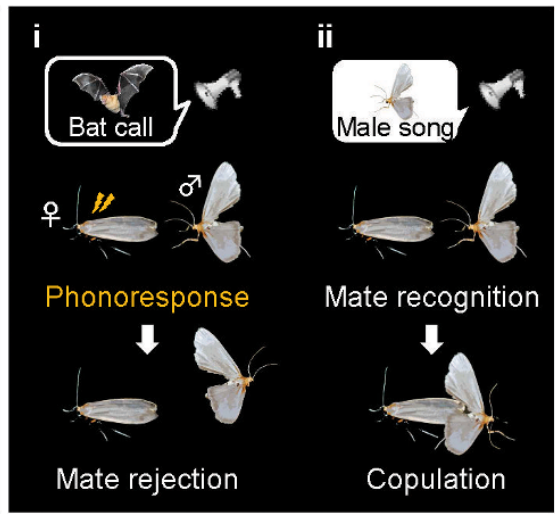

C

\section{Emergence}

of moths

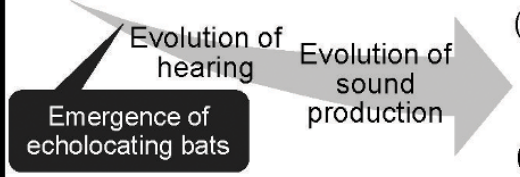

(a) Indiscriminable

$\Rightarrow$ Deceptive courtship song

(e.g., corn borer, cutworm)

\section{(b) Discriminable}

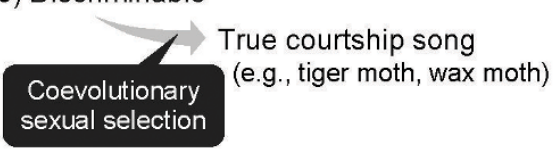

Figure $4 \mid$ Evolution of deceptive and true courtship songs in moths. (A) In the Asian corn borer, female receivers freeze in response to bat calls (i) and a male song (ii). The male signaler can easily copulate with the female immobilized by the deceptive signal. (B) In the Japanese lichen moth, females return phonoresponses to bat calls (i) but recognize the male sound as a courtship song (ii). The male signaler can copulate with the female that has become receptive. (C) A hypothesis on the evolutionary processes of deceptive and true courtship songs in moths. Deceptive courtship songs evolved from the sounds males incidentally emitted, which females were unable to discriminate from bat calls (a). On the other hand, true courtship songs evolved from the sounds males incidentally emitted, which females were able to discriminate from bat calls (b). In this case, male ultrasound is likely to have been meaningless at first but subsequently may have evolved into an attractive mating signal via coevolutionary sexual selection. The bat image is courtesy of M. B. Fenton.

distribution with a log link function for analyzing the number of copulation attempts in the Asian corn borer moth. In multiple comparisons, the critical p-value was calculated by controlling the false discovery rate.

Animals. Larvae of the Asian corn borer and the Japanese lichen moth were respectively collected from corn stems at Akiruno, Tokyo $\left(35^{\circ} \mathrm{N} 73^{\prime}, 139^{\circ} \mathrm{E} 30^{\prime}\right)$ in October 2008, and from lichen at the University of Tokyo (Bunkyo-ku, Tokyo, $\left.\mathrm{N} 35^{\circ} 72^{\prime}, \mathrm{E} 139^{\circ} 76^{\prime}\right)$ in June 2008 and 2009. Both species were reared on an artificial diet, Silkmate ${ }^{\mathrm{TM}} 2 \mathrm{M}$ (Nosan Corp., Yokohama, Japan), under conditions of $24^{\circ} \mathrm{C}$, $60-70 \%$ R.H., and a $16 \mathrm{~h}$ light: $8 \mathrm{~h}$ dark cycle ${ }^{15-17,31}$. Newly emerged male and female moths ( 0 days old) were separately transferred to $430-\mathrm{ml}$ plastic cups with a supply of water on a daily basis. Two-day-old virgin males and 2- to 4-day-old virgin females of the Asian corn borer and 1- to 2-day-old virgin adults of the Japanese lichen moth were used for experiments, which were conducted during the last $2 \mathrm{~h}$ of the scotophase when they showed high levels of mating activity ${ }^{31,32}$.

Sound stimuli. We synthesized five sound stimuli, i.e., a male courtship song, two types of bat calls, a continuous $40-\mathrm{kHz}$ sine wave, and background noise. The $40-\mathrm{kHz}$ sine wave was used as a representative of sounds without a pulsed structure. The male songs of the two moth species and background noises were recorded with a 1/4-inch (6.35-mm) condenser microphone (type 4939, Brüel \& Kjær, Nærum, Denmark). The tip of the microphone was set at a distance of $1 \mathrm{~cm}$ from a courting male in a cubic mesh cage $(18 \times 18 \times 18 \mathrm{~cm})$, which housed 5-8 males and 5-10 virgin females. When males in different pairs accidentally produced courting ultrasounds at the same time, although rare, the recorded courtship songs were discarded. The cage was placed in a one-side open soundproof box $(40 \times 70 \times 40 \mathrm{~cm} ; 0.2$ lux red light). Signals from the microphone were amplified by pre- and conditioning-amplifiers (type 2670 and 2690 with a $0.02-100 \mathrm{kHz}$ band-pass filter, Brüel \& Kjær). The signals were digitized at a sampling rate of $300 \mathrm{kHz}$ using a 12-bit A/D converter (Wavebook 512A, IOtech, Ohio, USA), and high-pass $(>10-\mathrm{kHz})$ filtered to eliminate low-frequency noises using the Butterworth filter built into the BatSound 3.31 software (Pettersson Elektronik AB, Uppsala, Sweden). The songs of the Asian corn borer (Figure 1A) consisted of a group of pulses and a silent inter-pulse-group interval [58-176 ms in total (pulse-group + inter-pulse-group interval)], whereas the songs of the Japanese lichen moth (Figure 1B) consisted of four- to eight-click pairs and a silent inter-clickpair interval (569-1082 ms in total). We edited recordings of the courtship songs of 20 male Asian corn borers and 19 male Japanese lichen moths using the software ARB-soft3 (TOYO Co., Tokyo, Japan), and the edited songs were reproduced using a function generator (type 5061 with a sampling rate of $300 \mathrm{kHz}, 14$-bit, Tabor Electronics Ltd., Tel Hanan, Israel). One unit (a pulse-group or a click-pair with an interval) of male song playbacks was continuously broadcast (looped) from a loudspeaker (model S56 with amplifier S55, UltraSound Advice, London, UK). Randomly selected background noises of $100 \mathrm{~ms}$ were also continuously presented. Simulations of bat echolocation calls were created using ARB-soft 3 with reference to vespertilionid bats (mouse-eared bats Myotis spp., pipistrelle bats Pipistrellus spp., and house bats Eptesicus spp.) and rhinolophid bats (horseshoe bats Rhinolophus spp.), which are moth-eating bats found in $\operatorname{Japan}^{33}$. Bats of Vespertilionidae (FM bats) use short ultrasonic pulses with a high to low frequency modulation (Figure 1C), whereas bats of Rhinolophidae (CF bats) use a long constant frequency ultrasonic pulse with initial and terminal transient $\mathrm{FM}^{34}$ (Figure 1D). Furthermore, echolocating bats change their calls depending on the distance to the target, i.e., search, approach, and terminal phase calls ${ }^{34}$. Flying and/or walking moths show evasive responses, i.e., a freezing response (cease to move when walking and drop to the ground when flying), looping flight, and/or a phonoresponse in response to approach and terminal phase calls $^{8,9,14,24,25,28,35}$. Accordingly, ultrasounds having the following temporal/spectral structures were designed as predatory bat calls with reference to the approach and terminal calls of FM and CF bats. FM bat call: downward FM of 80 - to $30-\mathrm{kHz}$ pulse of 3-, 4- or 5-ms duration including a $5 \%$ rise/fall time $\mathrm{e}^{34,36}$. CF bat call: an initial upward FM (1.5-ms pulse) of 56 to $68 \mathrm{kHz}$ including a $5 \%$ rise time followed by a $68-\mathrm{kHz}$ CF pulse of 20-, 25-, or 30-ms duration and a terminal downward FM (2.0-ms pulse) of 68 to $52 \mathrm{kHz}$ including a $5 \%$ fall time ${ }^{37}$. These pulses (FM pulses of 3-, 4-, or 5-ms duration, and CF pulses of 23.5-, 28.5-, or 33.5-ms duration including initial/terminal FM) were generated using the Tabor function generator with a sampling rate of $10 \mathrm{MHz}$ (14-bit) and broadcast by the loudspeaker at 44-56-pulse/s for FM bat calls (22 types in total) and at 15 to 30 -pulse/s for CF bat calls (22 types in total). In addition to these bat calls, a continuous $40-\mathrm{kHz}$ sine wave without pulse structures was synthesized using the function generator with a sampling rate of $10 \mathrm{MHz}$ (14-bit). 


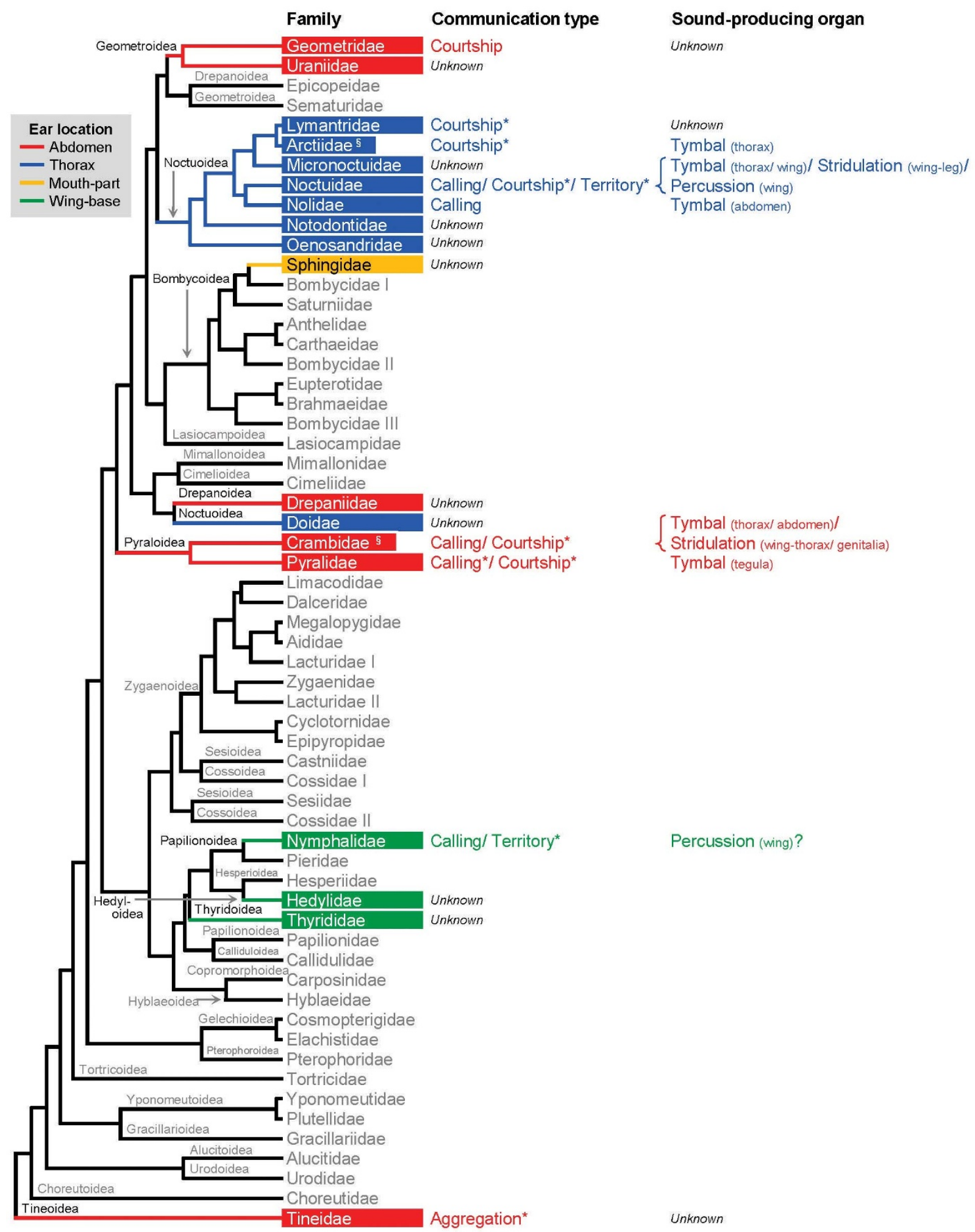

Figure $5 \mid$ Evolution of acoustic communication in moths. Features of intraspecific acoustic communication and hearing ${ }^{3,9-11,18}$ mapped onto a molecular phylogeny of Lepidoptera modified from Regier et al. ${ }^{40}$. Songs with verified function(s) are denoted with asterisks. ${ }^{5}$ The Asian corn borer moth and Japanese lichen moth belong to Crambidae and Arctiidae, respectively. Bombycidae, Lacturidae, and Cossidae are divided into a few groups denoted as I-III.

These stimuli were all broadcast $20 \mathrm{~cm}$ away from the moths under observation and the sound level at the position of the moths was 32-98 dB SPL (decibel sound pressure level, re. $20 \mu \mathrm{Pa}$; hereafter $\mathrm{dB}$ for brevity). The sound level was calibrated with reference to the signals of a sound level calibrator (type 4231, $94.00 \pm 0.20 \mathrm{~dB}$ at $1 \mathrm{kHz}$, Brüel \& Kjær). The sound pressure level of background noise (equivalent-continuous SPL re. $20 \mu \mathrm{Pa}, \mathrm{L}_{\text {eq }}$ ) was determined by the following equation using the sound levels of intermittent 10 -ms noises $(n=5)$ within the focal 100 -ms duration (20 noises in total):

$$
\mathrm{L}_{\mathrm{eq}}=10 \times \log _{10}\left(\sum 10^{\mathrm{Li} / 10} / \mathrm{n}\right)
$$

Here, $\mathrm{L}_{\mathrm{i}}$ denotes the sound pressure $(\mathrm{Pa})$ of the $\mathrm{i}$-th 10 -ms noise. 
Sound discrimination tests using the Asian corn borer Ostrinia furnacalis: female mate acceptance. For all surgical operations under a stereomicroscope, moths were anesthetized with $\mathrm{CO}_{2}$. To mute the males we removed the sound-producing scales on the forewings using fine forcep $\mathrm{s}^{16}$. A portion of ordinary scales on the forewings was removed for the sham-operation for muting. To deafen the males the tympanic membranes on the first abdominal segment were punctured using a fine insect pin ${ }^{15}$.

Five to ten intact females were first introduced into a flight tunnel $(2 \times 0.3 \mathrm{~m}$ diameter; $0.1 \mathrm{~m} / \mathrm{s}$ wind speed) and left undisturbed for a while, and then a single muted/sham-operated male was introduced. We observed the mate acceptance behaviors of the courted female until she accepted or rejected the muted male with the broadcast of the male song $(46 \mathrm{~dB}$, natural sound level of the songs of male Asian corn borers at a distance of $1 \mathrm{~cm}$, the average distance between a singing male and a receptive female $)^{16}$, background noise $(22 \mathrm{~dB}$, the sound level in the experimental room), $\mathrm{FM} / \mathrm{CF}$ bat call ( $74 \mathrm{~dB}$, a sound level representing a high predation risk to corn borers $)^{24}$, or continuous $40-\mathrm{kHz}$ sine wave $(46 \mathrm{~dB})$. Sham-operated males were used as controls, in which no playback stimulus was broadcast. The emission of ultrasounds from males and the loudspeaker was continuously monitored with an ultrasound detector (model D240X, Pettersson Elektronik AB). We observed mating behaviors of 14-35 unique pairs for each treatment.

Suppression of female escape behavior in the course of courtship. The effect of the sound stimuli on female escape behavior, which results in mate rejection, was examined in the flight tunnel using muted-and-deafened males with damaged genital claspers. The broadcast stimuli were the same as those described in the above section. The data for sham-operated males and muted males with playbacks of no sound, male song, and background noise were obtained from the previous study ${ }^{16}$. The number of copulation attempts accomplished by the sham-operated males emitting natural male songs was used as a positive control. We counted the number of male copulation attempts using 20 unique pairs for each treatment.

Cessation of pheromone release. Retraction of the abdominal tip (pheromone gland) by a female, which indicates the cessation of pheromone release, in response to the sound stimuli was observed ${ }^{24}$. Single intact females confined in a cylindrical mesh cage $(10 \times 9 \mathrm{~cm}$ diameter) were exposed to a single stimulus of either i) male songs, ii) FM bat calls, iii) CF bat calls, or iv) sine waves for $2 \mathrm{~s}$. Each sound was tested at eight sound levels (32-74 dB at $6 \mathrm{~dB}$ step) using different moths $(\mathrm{n}=15$ in each combination of sound stimuli and sound levels; $\mathrm{n}=120$ in each sound stimulus; $\mathrm{n}=$ 480 in total). Playback of the male song was used as a control.

Bat-avoidance response of flying moths. We examined the effects of various ultrasonic stimuli on tethered flying intact males and females in inducing evasive behavior. Flying moths tethered with a cotton thread by ligation between the second and third abdominal segments were exposed to i) male songs, ii) FM bat calls, iii) $\mathrm{CF}$ bat calls, and iv) sine waves at five sound levels (50-98 dB at $12 \mathrm{~dB}$ step) in random order for $2 \mathrm{~s}$ with intervals of at least $1 \mathrm{~min}$. We regarded flight cessation, looping flight, and steep turns as evasive behaviors taken by the moths in response to an attack by bats ${ }^{13,25}$. Playback of the male song was used as a control. We observed the evasive flight responses of 5-6 males and 5-6 females with 5-15 replicates in each combination of sound stimuli and sound levels. The same animal was used only within a series of experiments differing in the sound levels $(n=21$ males and 21 females in total).

\section{Sound discrimination tests using the Japanese lichen moth Eilema japonica} japonica: female mate acceptance. The sound-producing tymbal organs of the Japanese lichen moth are found on the metathoracic episterna, as in other arctiid moths ${ }^{12,38}$ (Figure 1B). To mute the males, we destroyed the tymbal membranes using fine forceps; the silencing of the males during courtship was confirmed with the recording system. The effect of muting females was examined in another experiment because females also possess functional tymbal organs. We punctured both lateral plates of the mesothorax for the sham-operation for muting. To deafen the females, we pierced the tympanic membranes on the postero-lateral metathorax using a fine insect pin. The postero-lateral mesothorax was punctured for the sham-operation for deafening. Five to ten virgin females from a treatment group (intact, deaf, or shamoperated) were first introduced into a cubic mesh cage placed in a one-side-opened soundproof box and were left undisturbed for some time. A single male from a treatment group (intact, muted, or sham-operated) was then introduced. Tested combinations (female $X$ male) were intact $X$ intact, deaf $X$ intact, sham $\times$ intact, intact $\times$ muted, intact $X$ sham, and muted $X$ intact. We observed the behavior of the courted female until she accepted (copulated) or rejected (escaped from) the male. In the normal courtship sequence, a wing-fanning and sound-emitting male approached walking, and then mounted the back of a receptive female before copulating. We observed the mating behaviors of 10-27 unique pairs for each treatment.

For playback experiments, muted males were further deafened so as to eliminate the effects of broadcasting sound stimuli on their courtship behaviors. Mate acceptance behaviors of the female were observed until she accepted or rejected the shamoperated males (control), or muted males with the broadcast of i) male songs, ii) background noise, iii) FM bat calls, or iv) CF bat calls. The pair of moths observed was removed from the cage, and the experiment was continued with a new male. The presence of other female moths did not affect the behavior of the male because females did not actively search for the male. The sound pressure levels of the broadcast were as follows: $62 \mathrm{~dB}$ for the male song (natural sound level at a distance of $1 \mathrm{~cm}$, the average distance between a singing male and receptive female ${ }^{18} ; 22 \mathrm{~dB}$ for background noise; and $98 \mathrm{~dB}$ for simulated FM/CF bat calls (a typical sound level of bat calls evoking a phonoresponse from tiger moths $)^{21,23,29}$. We observed the mating behaviors of $18-23$ unique pairs for each treatment.

Phonoresponse of stationary moths. Lichen moths and tiger moths are well known for sequestering defensive chemicals in their body and producing warning clicks (phonoresponse) against attacking bats ${ }^{12,39}$. The clicks were recorded by the microphone system described above. A stationary single intact male/female confined in a cylindrical mesh cage was exposed to the male song, FM bat call, and CF bat call in random order at $98 \mathrm{~dB}$ for $2 \mathrm{~s}$ with intervals of at least $1 \mathrm{~min}$. We recorded the phonoresponses of 10 males and 10-13 females with 5 replicates in each sound stimulus, and used the same animals repeatedly for different stimuli.

Bat-avoidance response of flying moths. The phonoresponse and evasive behavioral response of moths to ultrasonic stimuli were examined using tethered flying moths. A moth was tethered with a cotton thread by ligating the abdomen between the second and third segments and the flying moth was exposed to the set of sound stimuli described above. The phonoresponse was checked after the recordings, and the evasive response was observed directly by eye. We recorded the bat-avoidances of 6-8 flying males and 9-10 flying females with 3-10 replicates in each sound stimulus, and used the same animals repeatedly for different stimuli.

1. Endler, J. A. \& Basolo, A. Sensory ecology, receiver biases and sexual selection. Trend Ecol Evol 13, 415-420 (1998).

2. Ryan, M. J. Sexual selection, receiver biases, and the evolution of sex differences. Science 281, 1999-2003 (1998).

3. Greenfield, M. D. Signallers and Receivers: Mechanisms and Evolution of Arthropod Communication (Oxford Univ. Press, Oxford, 2002).

4. Arnqvist, G. Sensory exploitation and sexual conflict. Phil Trans R Soc B 361, 375-386 (2006)

5. Garcia, C. M. \& Ramirez, E. Evidence that sensory traps can evolve into honest signals. Nature 434, 501-505 (2005)

6. Kolm, N., Amcoff, M., Mann, R. P. \& Arnqvist, G. Diversification of a foodmimicking male ornament via sensory drive. Curr Biol 22, 1440-1443 (2012).

7. Proctor, H. C. Courtship in the water mite Neumania papillator: males capitalize on female adaptations for predation. Anim Behav 42, 589-598 (1991).

8. Greenfield, M. D. \& Hohendorf, H. Independence of sexual and anti-predator perceptual functions in an acoustic moth: implications for the receiver bias mechanism in signal evolution. Ethology 115, 1137-1149 (2009).

9. Spangler, H. G. Moth hearing, defense, and communication. Annu Rev Entomol 33, 59-81 (1988).

10. Conner, W. E. 'Un chant d'appel amoureux': acoustic communication in moths. J Exp Biol 202, 1711-1723 (1999).

11. Minet, J. \& Surlykke, A. in Lepidoptera, Moths and Butterflies. Vol. 2: Morphology, Physiology, and Development, ed Kristensen, N. P. (Walter de Gruyter, Berlin), pp. 289-323 (2003).

12. Conner, W. E. \& Corcoran, A. J. Sound strategies: the 65-million-year-old battle between bats and insects. Annu Rev Entomol 57, 21-39 (2012).

13. Yager, D. D. Predator detection and evasion by flying insects. Curr Opin Neurobiol 22, 201-207 (2012)

14. Greenfield, M. D. \& Weber, T. Evolution of ultrasonic signalling in wax moths: discrimination of ultrasonic mating calls from bat echolocation signals and the exploitation of an antipredator receiver bias by sexual advertisement. Ethol Ecol Evol 12, 259-279 (2000).

15. Nakano, R. et al. Ultrasonic courtship song in the Asian corn borer moth, Ostrinia furnacalis. Naturwissenschaften 93, 292-296 (2006).

16. Nakano, R. et al. Moths produce extremely quiet ultrasonic courtship songs by rubbing specialized scales. Proc Natl Acad Sci USA 105, 11812-11817 (2008).

17. Nakano, R. et al. Ultrasonic courtship songs of male Asian corn borer moths assist copulation attempts by making the females motionless. Physiol Entomol 35, 76-81 (2010).

18. Nakano, R. et al. Moths are not silent, but whisper ultrasonic courtship songs. J Exp Biol 212, 4072-4078 (2009).

19. Sanderford, M. V. \& Conner, W. E. Acoustic courtship communication in Syntomeida epilais Wlk. (Lepidoptera: Arctiidae, Ctenuchinae). J Insect Behav 8, 19-31 (1995).

20. Simmons, R. B. \& Conner, W. E. Ultrasonic signals in the defense and courtship of Euchaetes egle Drury and E. bolteri Stretch (Lepidoptera: Arctiidae). J Insect Behav 9, 909-919 (1996).

21. Barber, J. R. \& Conner, W. E. Acoustic mimicry in a predator-prey interaction. Proc Natl Acad Sci USA 104, 9331-9334 (2007).

22. Ratcliffe, J. M. \& Nydam, M. L. Multimodal warning signals for a multiple predator world. Nature 455, 96-99 (2008).

23. Corcoran, A. J., Barber, J. R. \& Conner, W. E. Tiger moth jams bat sonar. Science 325, 325-327 (2009).

24. Acharya, L. \& McNeil, J. N. Predation risk and mating behavior: the responses of moths to bat-like ultrasound. Behav Ecol 9, 552-558 (1998).

25. Roeder, K. D. Nerve Cells and Insect Behavior (Harvard Univ. Press, Cambridge, MA, ed. 3, 1998)

26. Yack, J. E. The structure and function of auditory chordotonal organs in insects. Microsc Res Tech 63, 315-337 (2004). 
27. Surlykke, A. \& Fullard, J. H. Hearing of the Australian whistling moth, Hecatesia thyridion. Naturwissenschaften 76, 132-134 (1989).

28. Skals, N. \& Surlykke, A. Hearing and evasive behaviour in the greater wax moth, Galleria mellonella (Pyralidae). Physiol Entomol 25, 354-362 (2000).

29. Fullard, J. H., Ratcliffe, J. M. \& Christie, C. G. Acoustic feature recognition in the dogbane tiger moth, Cycnia tenera. J Exp Biol 210, 2481-2488 (2007).

30. Nakano, R. et al. To females of a noctuid moth, male courtship songs are nothing more than bat echolocation calls. Biol Lett 6, 582-584 (2010).

31. Fujii, T. et al. Female sex pheromone of a lichen moth Eilema japonica (Arctiidae, Lithosiinae): components and control of production. J Insect Physiol 56, 1986-1991 (2010).

32. Huang, Y. P. et al. Geographic variation in sex pheromone of Asian corn borer, Ostrinia furnacalis, in Japan. J Chem Ecol 24, 2079-2088 (1998).

33. Yoshiyuki, M. A systematic study of the Japanese Chiroptera. Natl Sci Mus Monogr 7, 1-242 (1989).

34. Schnitzler, H.-U. \& Kalko, E. K. V. Echolocation by insect-eating bats. BioScience 51, 557-569 (2001).

35. Jones, G., Barabas, A., Elliott, W. \& Parsons, S. Female greater wax moths reduce sexual display behavior in relation to the potential risk of predation by echolocating bats. Behav Ecol 13, 375-380 (2002).

36. Surlykke, A. \& Moss, C. F. Echolocation behavior of big brown bats, Eptesicus fuscus, in the field and the laboratory. J Acoust Soc Am 108, 2419-2429 (2000).

37. Tian, B. \& Schnitzler, H.-U. Echolocation signals of the greater horseshoe bat (Rhinolophus ferrumequinum) in transfer flight and during landing. J Acoust Soc Am 101, 2347-2364 (1997).

38. Blest, A. D., Collett, T. S. \& Pye, J. D. The generation of ultrasonic signals by a New World arctiid moth. Proc R Soc B 158, 196-207 (1963).

39. Conner, W. E. Tiger Moths and Woolly Bears: Behavior, Ecology, and Evolution of the Arctiidae (Oxford Univ. Press, New York, 2009).
40. Regier, J. C. et al. Toward reconstructing the evolution of advanced moths and butterflies (Lepidoptera: Ditrysia): an initial molecular study. BMC Evol Biol 9, 280 (2009).

\section{Acknowledgments}

We are grateful to J. M. Ratcliffe and M. D. Greenfield for providing constructive advice on an earlier version of the manuscript, and to J. A. Simmons, S. Hiryu, Y. Sato, and M. B. Fenton for kindly providing bat photos. This study was supported by Grants-in-Aid from the Japan Society for the Promotion of Science (R.N., Y.I.), by the Danish Natural Science Research Council (N.S., A.S.), by a Research Fellowship of the Japan Society for the Promotion of Science for Young Scientists (R.N.), and by Inoue Research Aid for Young Scientists (R.N.)

\section{Author contributions}

R.N. designed and performed research. R.N., T.T., A.S., N.S. and Y.I. analyzed data and wrote the paper.

\section{Additional information}

Competing financial interests: The authors declare no competing financial interests.

How to cite this article: Nakano, R., Takanashi, T., Surlykke, A., Skals, N. \& Ishikawa, Y. Evolution of deceptive and true courtship songs in moths. Sci. Rep. 3, 2003; DOI:10.1038/ srep02003 (2013).

\footnotetext{
(c) (i) (s) $\odot$ This work is licensed under a Creative Commons Attribution-

NonCommercial-NoDerivs 3.0 Unported license. To view a copy of this license, visit http://creativecommons.org/licenses/by-nc-nd/3.0
} 